Jpn. J. Genet. (1989) 64, pp. 355-361

\title{
Chromosome variations in protoplast-derived calli and in plants regenerated from the calli of cultivated rice (Oryza sativa L.)
}

\author{
Soryu NishibaYASHI*, Yasuyuki HaYaSHI, Junko KyozUKa \\ and Ko Shimamoto \\ Plantech Research Institute, 1000 Kamoshida-cho, \\ Midori-ku, Yokohama 227
}

(Received 13 July 1989)

\begin{abstract}
Rice chromosomes were observed in protoplast-derived calli of two cultivars (japonica), and in plants regenerated from the calli of five cultivars (japonica). The chromosomal behavior was different between the two cultivars. In cv 'Nipponbare', most cells observed were stable in a diploid state $(2 \mathrm{n}=24)$ during protoplast culture. In $\mathrm{cv}$ 'Iwaimochi', on the contrary, diploid, tetraploid, aneuploid and octoploid cells were present chimerically in calli. It is suggested that the appearance of polyploid cells in $\mathrm{cv}$ 'Iwaimochi', might have resulted in endopolyploidy during protoplast culture. In the forty-three regenerants observed in the four cultivars including 'Nipponbare' forty-two were diploids, while in cv 'Iwaimochi' tetraploid plants were regenerated at a higher frequency (6/11 plants), compared to the other four cultivars ( $1 / 43$ plant). Therefore, the high frequency of tetraploid regenerants seems to correlate with the chimeric presence of diploid and tetraploid cells in calli.
\end{abstract}

\section{INTRODUCTION}

Phenotypic variations in regenerants, indicating occurrence of somaclonal variation (Larkin and Scowcroft, 1981) during culture, have been found in several higher plants (Shepard et al., 1980; Evans and Sharp, 1983). Also in rice (Oryza sativa L.) somaclonal variations have been more frequently observed in plants regenerated from anther and from tissue culture (Nishi et al., 1968; Niizeki and Oono, 1971; Fukui, 1983; Sun et al., 1983; Oono, 1985). Cytological investigations revealed that the number of chromosome varied highly in anther-derived calli and in their regenerants (Nishi and Mitsuoka, 1969; Oono, 1975; Chen and Chen, 1980). Haploid and diploid plants were regenerated from protoplast culture in anther calli (Toriyama et al., 1986). Previously Ogura et al., (1987) counted chromosome numibers in regenerants from protoplast-derived calli in four cultivars of rice. Most plants exhibited diploid chromosome number. But in two cultivars tetraploid plants were highly regenerated from calli.

* Corresponding author. 
We further observed chromosomal behavior during protoplast culture and chromosomes in regenerants of rice, to investigate the reason of appearance of somaclonal variants with polyploid chromosome number.

\section{MATERIALS AND METHODS}

Methods of protoplast isolation and culture were described in detail in the previous report by Kyozuka et al. (1987). Immature embryo- and mature seedderived calli from five cultivars of rice (japonica) were used as protoplast sources. Chromosomes in protoplast-derived calli were observed in two cultivars of 'Nipponbare' and 'Iwaimochi'. Protoplasts were isolated from about 3-month old suspension cells of mature seed-derived calli of these cultivars, and they were cultured in R2 medium and mini-colonies formed were transferred to N6 medium. Chromosomes were observed in two-month old calli after protoplast isolation. On the contrary, protoplast culture in five cultivars regenerated was the same as in the previous report (Kyozuka et al., 1987). Regeneration from calli were conducted in N6 medium containing different concentrations of various cytokinins. Plantlets were explanted into pots and grown in a green house. Chromosomes were observed in root-tip cells of plants. Preparations for chromosomal observations were made by the enzymatic maceration method (Nishibayashi and Kaeriyama, 1986), which was a modified method of Kurata and Omura (1978). Chromosomes in the cells of protoplast-derived calli were stained with the DNA-specific dye ethidium bromide and observed with an epifluorescence microscope (Kuroiwa et al., 1982; Terada et al., 1987). Chromosomes in the root-tip cells of regenerants were stained with aceto-orcein and observed with a light microscope.

\section{OBSERVATIONS AND DISCUSSION}

As shown in Table 1 and Fig. 1, chromosomal behavior in protoplast-derived calli was different between the two cultivars. In cv 'Nipponbare', most cells observed were stable in a diploid state $(2 n=24)$, except for rarely observed tetraploid cells (Table 1, Fig. 1A). On the contrary, the chromosome numbers in cv 'Iwaimochi' were mainly 24 , next 48 , rarely 23,47 and ca. 96 (Table 1, Figs. $1 \mathrm{~B}$ and 1C). In this cultivar, polyploid cells appeared at a high frequency (maximum 22.6\%) during protoplast culture, compared to the cv 'Nipponbare' (maximum $3.1 \%$ ). The cells with these chromosome numbers were chimerically present in calli, while cells in a small-sized callus exhibited only a diploid chromosome number.

It is generally well-known that polyploid cells often appear during cell and tissue culture by endopolyploidy (Nagl and Rücker, 1974; Sunderland, 1977; D'Amato, 1978; Bayliss, 1980). Therefore, it is suggested that the appearance of 

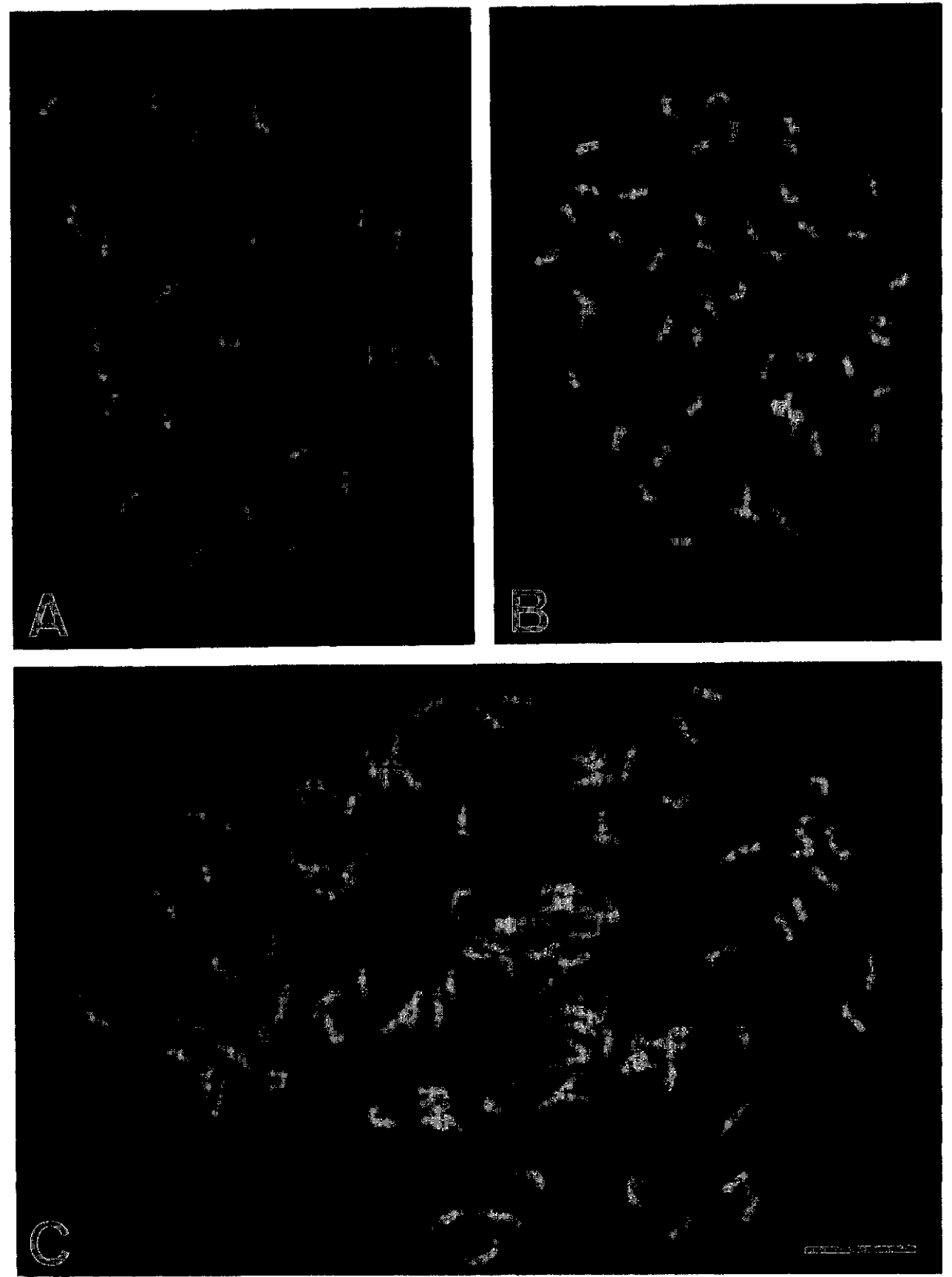

Fig. 1. Epifluorescent micrographs of ethidium bromide-stained chromosome in cells of protoplastderived calli of two rice cultivars. A, cv 'Nipponbare' $(2 n=24)$. B, ev 'Iwaimochi' $(2 n=48)$. C, cv 'Iwaimochi' $(2 \mathrm{n}=$ ca.96). Bar indicates $10 \mu \mathrm{m}$. 
Table 1. Chromosome numbers of cells with growth of protoplast-derived calli in rice cv 'Nipponbare' and ev 'Iwaimochi'

\begin{tabular}{|c|c|c|c|c|c|c|c|c|}
\hline \multirow{2}{*}{ Cultivar } & \multirow{2}{*}{$\begin{array}{c}\text { Callus } \\
\text { Number }\end{array}$} & \multirow{2}{*}{$\begin{array}{c}\text { Callus } \\
\text { Size } \\
(\mathrm{mm}) \times(\mathrm{mm})\end{array}$} & \multicolumn{5}{|c|}{ Chromosome number } & \multirow{2}{*}{$\begin{array}{l}\text { Percentage of } \\
\text { polyploid cells }\end{array}$} \\
\hline & & & 23 & 24 & 47 & 48 & $8 x$ & \\
\hline \multirow[t]{4}{*}{ Nipponbare } & 1 & $2 \times 2$ & & 18 & & & & \\
\hline & 2 & $3 \times 3$ & & 35 & & 1 & & 2.7 \\
\hline & 3 & $3 \times 3$ & & 31 & & 1 & & 3.1 \\
\hline & 4 & $3 \times 4$ & & 27 & & & & \\
\hline \multirow[t]{4}{*}{ Iwaimochi } & 1 & $2 \times 2$ & 2 & 33 & & & & \\
\hline & 2 & $2 \times 3$ & & 26 & & 3 & & 10.3 \\
\hline & 3 & $3 \times 3$ & & 48 & 1 & 11 & 2 & 22.6 \\
\hline & 4 & $4 \times 4$ & & 27 & & 7 & & 20.6 \\
\hline
\end{tabular}

tetraploid cells in $\mathrm{cv}$ 'Iwaimochi' might have resulted in endopolyploidy during protoplast culture.

Chromosome number observed in regenerants of five cultivars is shown in Table 2. All 14 regenerants observed in cv 'Nipponbare' were diploids (Table 2, Fig. $2 \mathrm{~A}$ ). In the present protoplast culture, $2-3 \mathrm{~mm}$ sized calli are usually transferred to the regeneration medium (Kyozuka et al., 1987). As shown in Table 1, most cells (111/113 cells) of $2-4 \mathrm{~mm}$ sized calli in cv 'Nipponbare' exhibited a diploid chromosome number. Therefore, the chromosome number seems to be stable also during regeneration in this cultivar. In cvs 'Fujisaka-5', 'Koshihikari' (Fig. 2B) and 'Norin-14', most regenerants (42/43 plants) observed were also diploid, but in cv 'Norin-14' one regenerant was tetraploid (Table 2).

Previously Ogura et al. (1987) observed that in thirteen regenerants in cv 'Norin-14' two were tetraploids. On the contrary, in cv 'Iwaimochi' tetraploid plants were regenerated at a higher frequency (6/11 plants), compared to the other four cultivars (1/43 plant) (Table 2, Figs. 2A-C). Ogura et al. (1987) also observed that in twenty-nine regenerants in cv 'Iwaimochi', one was aneuploid and four were tetraploids. The high frequency of tetraploid regenerants seems to correlate with the chimeric presence of diploid and tetraploid cells in calli.

Morphological characteristics for plant height, panicle length, panicle number, grain number and seed fertility were variable in regenerants of cvs 'Norin-14' and 'Iwaimochi' observed. Particularly in tetraploid regenerants of cv 'Iwaimochi'. grain number and seed fertility were very low, compared to control plants. Phenotypic variations have been more frequently $(71.9-75.4 \%)$ observed in rice plants regenerated from somatic tissue culture (Oono, 1975; Fukui, 1983; Sun et al., 1983). These phenotypic variations are considered to be caused during culture or regeneration by somaclonal variations.

In the present rice-protoplast culture, chromosomal behavior is classified into 

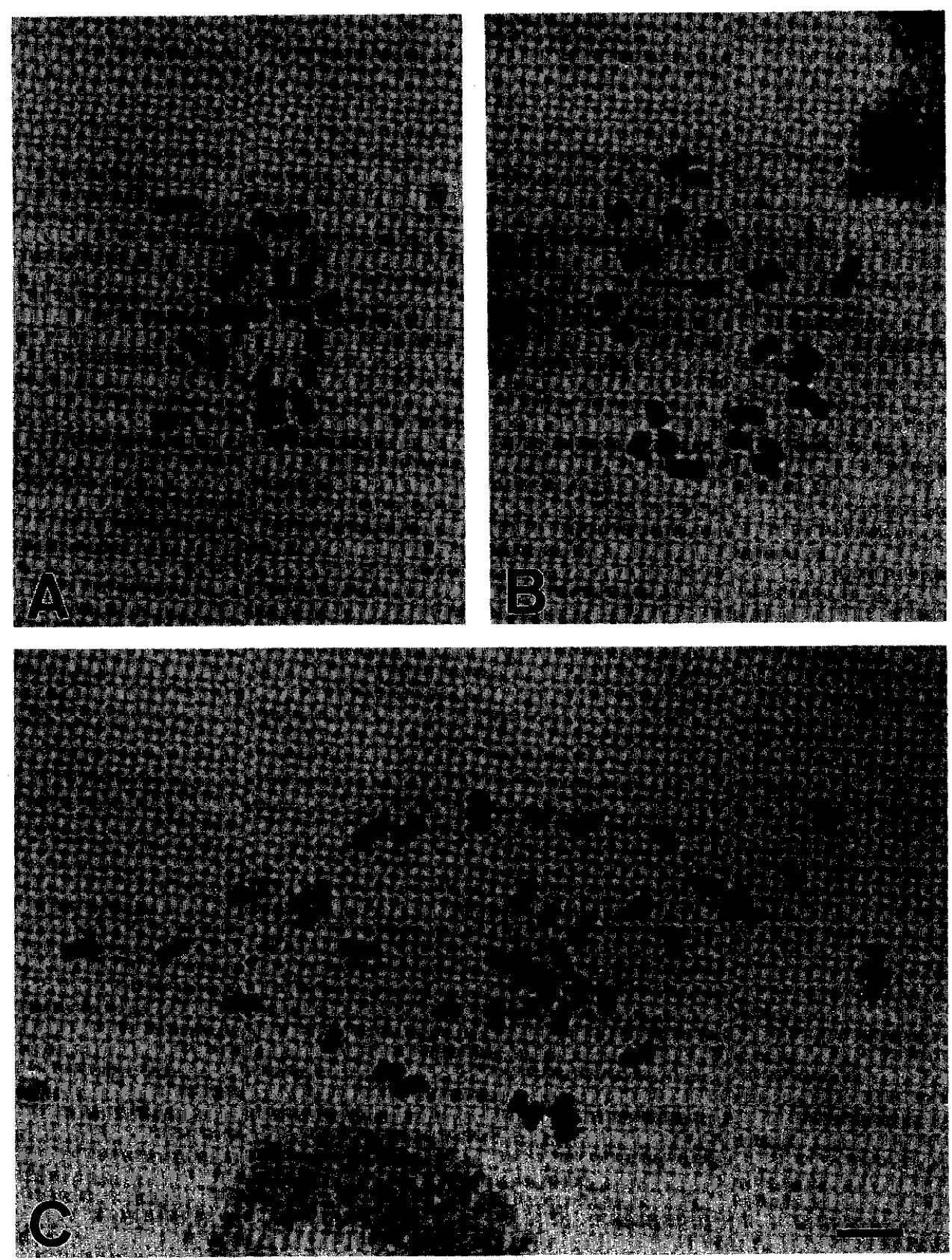

Fig. 2. Light micrographs of aceto orcein-stained chromosomes in root-tip cells of plants regenerated from protoplast-derived calli of three rice cultivars. A, cv 'Nipponbare' $(2 n=24)$. B, cv 'Koshihikari' $(2 n=24)$. C, cv 'Iwaimochi' $(2 n=48)$. Bar indicates $5 \mu \mathrm{m}$. 
Table 2. Chromosome number of plants regenerated from protoplast-derived calli in five cultivars of rice

\begin{tabular}{lcc}
\hline \multirow{2}{*}{ Cultivar } & \multicolumn{2}{c}{$\begin{array}{c}\text { Chromosome number } \\
\text { of plants regenerated }\end{array}$} \\
\cline { 2 - 3 } & 24 & 48 \\
\hline Nipponbare & 14 & \\
Koshihikari & 7 & \\
Fujisaka-5 & 8 & 1 \\
Norin-14 & 13 & 6 \\
Iwaimochi & 5 & 6 \\
\hline
\end{tabular}

two types. One is a stable type with a diploid state $(2 n=24)$ during protoplast culture (Nipponbare type), and another is an unstable type with aneuploid and particularly polyploid cells during protoplast culture (Iwaimochi type). As previously reported (Sun et al., 1983), the frequency of regeneration of polyploid plants in tissue culture ranged from $0-13.3 \%$ in nine varieties of 'Hsien' (indica) group, but no polyploid plant was found in nine varieties of 'Keng' (japonica) group. On the contrary, polyploid ( $4 / 7$ ones) and aneuploid (2/7 ones) plants were regenerated from protoplast-derived calli in long term culture in cv 'Norin-8' (Kanda et al., 1988). However, in this case, chromosomes in the cells of calli were not observed. The present study showed that chromosomal behavior in protoplast-derived calli was different between two cultivars, and also showed that the regeneration of somaclonal variants with polyploid chromosome number resulted in the appearance of polyploid cells during protoplast culture.

We would like to thank Prof. Dr. R. Tanaka, Hiroshima University for critical reading of the manuscript and Prof. Dr. T. Kuroiwa, University of Tokyo for technical advice in epifluorescence microscopy, and also to thank colleagues at the Plantech Research Institute for their helpful discussions. Thanks are also due to Miss C. Mukai and Miss K. Itoh for their technical assistance in the chromosome analysis.

\section{REFERENCES}

BayLiss, M. W. (1980) Chromosomal variation in plant tissue in culture. Int. Rev. Cytol. (Suppl.) 11A, 113-144.

CHEN, C. C. and CHEN, C. M. (1980) Changes in chromosome number in microspore callus of rice during successive subcultures. Can. J. Genet. Cytol. 22, 607-614.

D'AMATO, F. (1978) Chromosome number variation in cultured cells and regenrated plants. In: Frontiers of Plant Tissue Culture (ed.: T. A.Thorpe), pp. 287-295. Academic Press, New York.

EVANS, D. A. and ShaRP, W. R. (1983) Single gene mutations in tomato plants regenerated from tissue culture. Science 221, 949-951. 
FukUI, K. (1983) Sequential occurrence of mutations in a growing rice callus. Theor. Appl. Genet. 65, 225-230.

KANDA, M., KIKUCHI, S., TAKAIWA, F. and OONO, K. (1988) Regeneration of variant plants from rice (Oryza sativa L.) protoplasts derived from long term cultures. Jpn. J. Genet. 63, 127-136.

KurAtA, N. and OMURA, T. (1978) Karyotype analysis in rice. 1. A new method for identifying all chromosome pairs. Jpm. J. Genet. 53, 251-255.

Kuroiwa, T., Kawano, S., Nishibayashi, S. and Sato, C. (1982) Epifluorescent microscopic evidence for maternal inheritance of chloroplast DNA. Nature 298, 481-483.

KYOZUKA, J., HAYASHI, Y. and SHIMAMOTO, K. (1987) High frequency plant regeneration from rice protopalsts by novel nurse culture methods. Mol. Gen. Genet. 60, 197-214.

LARKIN, P. J. and SCOWCROFT, W. R. (1981) Somaclonal variation-a novel source of variability from cell cultures for plant improvement. Theor. Appl. Genet. 60, 197-214.

NAGL, W. and RÜCKER, W. (1974) Shift of DNA replication from diploid to polyploid cells in cytokinin-controlled differentiation. Cytobios 10, 137-144.

NIIZEKI, H. and Oono, K. (1971) Rice plants obtained by anther culture. Les Culture de Tissue de Plantes 193, 251-257.

Nishi, T., YAMADA, Y. and TAKAHASHI, E. (1968) Organ redifferentiation and plant restoration in rice callus. Nature 219, 508-509.

NISHI, T. and MITSUOKA, S. (1969) Occurrence of various ploidy plants from anther and ovary culture of rice plant. Jpn. J. Genet. 44, 341-346.

NishIBAYASHI, S. and KAERIYAMA, J. (1986) Structural stability of chromosomes in rice (Oryza sativa L.) plants regenerated from somatic tissue culture. Plant Tissue Cult. Lett. 3, 31-34.

OGura, H., Kyozuka, J., Hayashi, Y., KoBa, T. and Shimamoto, K. (1987) Field performance and cytology of protoplast-derived rice (Oryza sativa): high yield and low degree of variation of four japonica cultivars. Theor. Appl. Genet. 74, 670-676.

OoNo, K. (1975) Production of haploid plants of rice (Oryza sativa) by anther culture and their use for breeding. Bull. Natl. Inst. Agric. Sci. Ser. D 26, 139-222.

OoNo, K. (1985) Putative homozygous mutations in regenerated plants of rice. Mol. Gen. Genet. 198, 377-384.

ShePARD, J. F., Bidney, D. and Shahin, E. (1980) Potato protoplasts in crop improvement. Science 208, 17-24.

Sun, Z. X., ZHAO, C. .Z., ZHENG, K. I., QI, X. F. and FU, Y. P. (1983) Somaclonal genetics of rice, Oryza sativa L. Theor. Appl. Genet. 67, 67-70.

Sunderland, N. (1977) Nuclear cytology. In: Plant Tissue and Cell Culture. (ed.: H. E. Street), pp. 177-205. University of California Press, Los Angeles.

Terada, R., Kyozuka, J., Nishibayashi, S. and Shimamoto, K. (1987) Plantlet regeneration from somatic hybrids of rice (Oryza sativa L.) and barnyard grass (Echinochloa oryzicola Vasing). Mol. Gen. Genet. 210, 39-43.

Toriyama, K., Hinata, K. and SASAKI, T. (1986) Haploid and diploid plant regeneration from protoplasts of anther callus in rice. Theor. Appl. Genet. 73, 16-19. 